\title{
PUBLICIDAD ENGAÑOSA EN EDUCACIÓN SUPERIOR: DEFINICIONES, REGULACIÓN Y UNA REVISIÓN DE LA PUBLICIDAD EN PRENSA ESCRITA $^{1}$
}

\author{
Gonzalo Zapata ${ }^{2}$ \\ Ivo Tejeda ${ }^{3}$
}

\begin{abstract}
RESUMEN
Este artículo sintetiza parte de una investigación que abordó el problema de la publicidad engañosa en universidades chilenas. Mediante la revisión de la literatura, el examen a la publicidad en prensa escrita y opiniones de especialistas y estudiantes, se levantó un marco conceptual, un panorama de la publicidad y su regulación en Chile, y se discutieron sus alcances desde el punto de vista de las políticas públicas. La regulación de la publicidad -y la promoción de la información y de la transparencia, en general- es clave para sentar las bases de confianza del sistema. Se propone para lo anterior no solo un mayor control estatal, sino también una fuerte autorregulación y empoderamiento de los estudiantes y demás actores del sistema.
\end{abstract}

Palabras clave: publicidad en educación superior, universidades chilenas, publicidad engañosa.

\section{MISLEADING ADVERTISING IN HIGHER EDUCATION: DEFINITIONS, REGULATIONS, AND A REVIEW OF WRITTEN PRESS ADVERTISING}

\section{ABSTRACT}

This paper summarizes part of a project that addresses the issue of misleading advertising in Chilean universities. Through reviewing the literature, examining newspaper advertising and the opinion of specialists and students, this work offers a conceptual framework, an overview of newspaper advertising and its regulation in Chile, and a discussion of its scope from a public policy perspective. The regulation of advertising -and the promotion of information and transparency, in general-is crucial for laying a foundation of trust in the higher education system. We suggest not only greater state control but also a strong self-regulation and empowerment of students and other stakeholders.

Keywords: higher education advertising, Chilean universities, misleading advertising.

1 Este artículo reporta parte de los resultados del proyecto de investigación "Publicidad y transparencia en educación superior en Chile", proyecto apoyado financieramente por CNED/ Convocatoria 2014. Se agradece a Daniela Horta, Daniela Contreras y Javier González, estudiantes de la P. Universidad Católica de Chile, quienes colaboraron como ayudantes en el equipo de investigación.

2 Pontificia Universidad Católica de Chile, Facultad de Educación, Santiago, Chile. Contacto: gonzalozapata@uc.cl

3 Santiago, Chile. Contacto: ivonicolas@gmail.com 


\section{Introducción}

La publicidad engañosa ha sido identificada como uno de los varios problemas actuales en la educación superior, que aparece en un contexto de excesiva desregulación, exacerbada competencia, excepcional privatismo y falta de transparencia en el sistema (Brunner, 2008a; Espinoza, 2005; Meller, 2004, 2011; Zapata y Fleet, 2012). El Consejo Nacional de Educación (CNED) ha abordado este problema en dos de sus seminarios internacionales, discutiendo la necesidad de mejorar la información y transparencia y estableciendo nuevas regulaciones y políticas que contribuyen a un mayor acceso y equidad en la educación superior (Consejo Superior de Educación, CSE, 2001, 2011).

Salvo por algunas referencias y estudios relativos al alto gasto en publicidad (Brunner, 2004; Sotomayor y Muga, 2004; Worner y Santander, 2012), prácticamente no existe investigación empírica disponible que dé cuenta de la publicidad en educación superior en Chile, mucho menos de su carácter engañoso. En cambio, abundan los ensayos relativos a los daños que generan los excesos en materia de publicidad y antecedentes respecto de los abusos que han cometido varias instituciones de educación superior (Cámara de Diputados, 2012; Guzmán, 2014; Meller, 2011; Monckeberg, 2011; Peña, 2011; Squella, 2001; Zapata, 2011).

En Chile, desde hace ya bastante tiempo que se ha venido planteando la necesidad de avanzar en la regulación de la publicidad $\mathrm{y}$, desde un punto de vista más amplio, en perfeccionar los sistemas de información y transparencia de la educación superior (Brunner et al., 2005; OECD, 2009). Hay ciertamente avances en la materia, como es la atribución del Ministerio de Educación de mantener un sistema nacional de información en educación superior y la introducción de algunas normas respecto de los contenidos de la acreditación en la publicidad de las instituciones (Ley N $\mathrm{N}^{\circ}$ 20.129, 2006), o bien la legislación en cuanto a protección de los derechos de los consumidores (Ley No 19.496, 1997), particularmente sus modificaciones introducidas en los años 2004 y 2011 sobre condiciones de las prestaciones en educación. Con todo, persisten 
importantes insuficiencias en el marco jurídico. Aunque se aprecia un relativo consenso respecto de la necesidad de regular un conjunto amplio de malas prácticas y abusos en el campo de la educación superior (que incluyen, entre otras, a la publicidad engañosa) y pese a las varias iniciativas de los anteriores gobiernos sobre la materia, el sistema político no ha sido capaz aún de alcanzar acuerdos y reformar su marco regulatorio en el campo.

Ya el informe de la Comisión de Estudio de la Educación Superior (1991) proponía que era indispensable ampliar las funciones de superintendencia a todo el sistema, asegurando información transparente y velando por la fe pública depositada en ella. En la discusión correspondiente al primer trámite constitucional sobre el proyecto de ley de superintendencia presentado por la anterior administración (Presidencia de la República, 2011), se planteó una gran preocupación respecto de la publicidad engañosa y sus consecuencias, sin embargo, también se manifestó la poca evidencia empírica existente y la dificultad para abordar el tema (Senado de la República de Chile, 2013). Dicho proyecto de ley fue archivado por la actual administración, anunciándose el envío de un nuevo proyecto de ley de reforma de la educación superior, mucho más amplio, y que abordaría diversas materias de regulación y gobierno del sistema.

La falta de investigación empírica y sistematización de la literatura, así como la necesidad de avanzar en una noción más comprensiva del concepto de publicidad engañosa, fundamentaron la presentación del proyecto "Publicidad y transparencia en educación superior en Chile", adjudicado por el CNED en su convocatoria del año 2014.

El principal objetivo del proyecto fue:

(...) analizar la publicidad de las universidades chilenas en medios de prensa escrita (sus características básicas, formato y tendencias de contenido) e identificar ámbitos posibles de aplicación de la noción de publicidad engañosa a partir de la revisión de literatura, opinión de expertos y percepciones de estudiantes acerca de contenidos de publicidad que potencialmente pueden inducir a error o engaño (Zapata y Tejeda, 2014, p. 3). 
El estudio se propuso contribuir a un debate que no ha sido fácil, levantando evidencia empírica acerca de la publicidad de nuestras instituciones en Chile y discutir los alcances de la noción de publicidad engañosa desde el punto de vista de las políticas públicas.

Considerando limitaciones de tiempo y recursos, al mismo tiempo que se trataba de uno de los primeros estudios de esta naturaleza en el campo de la educación superior, se optó por focalizar el análisis de la publicidad en las universidades del país (postergando, en esta oportunidad, la publicidad de institutos profesionales y centros de formación técnica) y realizar un levantamiento de la publicidad solo en formatos tradicionales para prensa escrita (dejando fuera medios de televisión, radio y redes sociales, entre las más importantes). Por su parte, se analizó el concepto de publicidad engañosa en Chile a partir de un examen de la literatura, casuística y opiniones de especialistas y estudiantes.

Los antecedentes recogidos en esta investigación han permitido levantar abundante evidencia empírica y muestras en torno a la materia. Este artículo sintetiza solo algunos de los hallazgos del estudio, aportando datos acerca de la publicidad de las universidades chilenas y la percepción que tienen especialistas y estudiantes al respecto, como así también un marco conceptual para comprender mejor el problema de la publicidad engañosa y su abordaje desde el punto de vista de la política pública.

\section{Diseño metodológico y trabajo de campo}

El estudio utilizó un diseño de carácter exploratorio, fundamentalmente de tipo descriptivo, debido a la falta de desarrollo conceptual e investigación empírica previa acerca de la publicidad engañosa en el campo de la educación superior. Se optó por el uso de metodologías mixtas, tanto cuantitativas como cualitativas (Creswell y Clark, 2007). Los objetivos específicos se delinearon del siguiente modo: a) sistematizar la literatura nacional e internacional previa en torno al tema; b) describir las principales características y regularidades de la publicidad en universidades chilenas en medios seleccionados (prensa escrita), tanto en lo referido a sus estrategias de publicidad, 
como a nivel de su contenido; c) examinar el concepto de publicidad engañosa y los posibles ámbitos en los que puede ser aplicada; y d) explorar las percepciones de estudiantes respecto de la publicidad en educación superior y sus nociones de publicidad engañosa.

Para los efectos de sistematizar la literatura, se revisaron distintos cuerpos bibliográficos que hasta la fecha habían mantenido escasa conexión entre sí. En este sentido, se revisó la poca investigación disponible en publicidad en educación superior, y se complementó con los debates acerca de publicidad engañosa que cuentan con bastante más desarrollo en las áreas del derecho comercial y de los consumidores, la publicidad y el marketing. Estos cuerpos de literatura fueron sistematizados para ofrecer un marco conceptual que permitiera abordar las nociones de publicidad engañosa en educación superior, sus problemas y vacíos.

Se realizó un levantamiento de toda la publicidad de las universidades chilenas en prensa escrita durante los meses de noviembre y diciembre de 2014, y de enero, febrero y marzo de 2015. Se trata del periodo de mayor presencia publicitaria de las universidades en medios escritos, coincidentemente con los distintos procesos y momentos de admisión a la educación superior. La publicidad fue seleccionada a partir de un servicio de monitoreo de prensa, que identificó todos los avisos publicados en la docena de periódicos de circulación metropolitana, a lo que se sumaron más de 30 periódicos regionales y cerca de 100 revistas y suplementos especializados de circulación nacional. La muestra no incluyó, en esta oportunidad, publicidad en medios digitales, redes sociales, radio ni televisión.

La muestra de publicidad levantada incluyó 4.644 piezas publicitarias. Cada aviso fue individualizado según la universidad a la que correspondía, un detalle de la fecha y medio en el que fue publicado, su ubicación (página) y tamaño (centímetros).

Por su parte, se construyó una base de datos y cada una de las piezas publicitarias fue codificada independientemente, consignándose un conjunto amplio de descriptores y atributos: 
- emisor (que puede ser la universidad o alguna de sus unidades: sedes, facultades, programas, dirección, etc.);

- uso de colores y logos, cuando existían;

- uso de imagen o imágenes, tamaño y su descripción;

- protagonista, género y principal acción, en el caso de los avisos con imágenes;

- detalle del encabezado, subencabezado (hasta un tercer nivel) y cuerpo del texto del aviso;

- información acerca de la acreditación institucional y de los programas;

- información acerca de otras certificaciones, redes o asociaciones, cuando existía;

- descripción de los principales atributos del aviso;

- principales mensajes transmitidos; y

- observaciones adicionales, cuando las había.

En la definición de los descriptores y atributos, se utilizaron categorías propias del estudio de la publicidad, en particular aquellas asociadas a comunicaciones masivas unidireccionales relacionadas con diferentes audiencias en educación superior (Constantinides y Zinck Stagno, 2011; Constantinides y Zinck Stagno, 2013; Kittle, 2000). Se prestó especial atención al contenido de los mensajes (Semprini, 1995; Sevier, 2001) y a los elementos diferenciadores que se estructuran en un aviso publicitario (Curubeto, 2007). Las categorías fueron levantadas utilizando, en parte, el trabajo adelantado por Carlos Curubeto (2007) en su estudio sobre marcas universitarias en Buenos Aires y, en parte, con ajustes introducidos de modo inductivo por los autores, luego de examinar el discurso de los textos (Delgado, 1997; Fairweather, 2009) e imágenes (Klassen, 2001) que preferentemente han adoptado las universidades en Chile en su publicidad en prensa escrita.

El examen del concepto de publicidad engañosa se realizó en primera instancia a partir de la revisión bibliográfica antes indicada. En efecto, la literatura nacional e internacional ofrece definiciones que fueron útiles para discutir en el campo de la educación superior. Adicionalmente, se complementó el análisis con antecedentes jurídicos 
y casuística en tribunales de justicia sobre publicidad engañosa en educación superior en Chile, antecedentes que fueron relevantes para comprender el dinamismo de un concepto que ha evolucionado en los últimos 25 años.

En el estudio se entrevistó a 11 especialistas, seleccionados tanto por su relación con organizaciones responsables de las políticas públicas y/o regulación en materia de educación superior, como por su experiencia en organizaciones que se han dedicado al estudio y trabajo en temas de consumo y publicidad. Entre los informantes clave se incluyó a especialistas de: organismos públicos en educación superior (Ministerio de Educación, Mineduc; División de Educación Superior, Divesup; Consejo Nacional de Educación, CNED; Comisión Nacional de Acreditación, CNA Chile); organizaciones de protección a los consumidores (Servicio Nacional del Consumidor, Sernac; una organización de consumidores; y un estudio de abogados especializado en el tema); de las asociaciones de medios y agencias de publicidad (Consejo de Autorregulación y Ética Publicitaria, Conar); y académicos universitarios.

Se utilizó una pauta semiestructurada de entrevista, que cubrió los siguientes temas:

- ¿Qué se entiende por publicidad engañosa?

- ¿Cómo puede ser tipificada?

- ¿Qué dice la casuística y jurisprudencia respecto del tratamiento de casos de publicidad engañosa?

- ¿Qué fortalezas o debilidades existen en el actual marco jurídico al respecto?

Los entrevistados contribuyeron aportando diversos antecedentes y opiniones acerca de las nociones y regulación de la publicidad engañosa en el país, enriqueciendo el análisis bibliográfico.

Finalmente, se realizaron cuatro focus groups a estudiantes, explorando sus percepciones en torno al concepto de publicidad engañosa. Interesaba conocer las percepciones de estudiantes de educación media que estaban postulando a la educación superior, así como de estudiantes universitarios, toda vez que se trata 
de los principales actores a los que está dirigida la publicidad de las instituciones. Considerando que la literatura sugiere importantes niveles de diferenciación institucional y estratificación socioeconómica en la educación superior chilena (Espinoza, 2008; Latorre, González y Espinoza, 2008; OCDE, 2009), se establecieron categorías bastante gruesas (tipo de universidad y ubicación geográfica de los establecimientos) destinadas a explorar cuánto de la inequidad del sistema podría expresarse en segmentación de audiencias con percepciones distintas respecto de la publicidad de las universidades.

De acuerdo con lo anterior, se realizó un muestreo intencionado, procurándose heterogeneidad en términos de género, áreas de interés/carreras y establecimientos/instituciones de estudio, pero homogeneidad desde el punto de vista del tipo de instituciones y nivel socioeconómico de los participantes seleccionados. Los cuatro grupos fueron organizados del siguiente modo: estudiantes de $4^{\circ}$ medio de Santiago-Oriente, que aspiraban a universidades de investigación (complejas y altamente selectivas); estudiantes de $4^{\circ}$ medio de Santiago-Poniente, que postulan a universidades docentes (privadas, no selectivas); estudiantes de primer año de universidades de investigación (complejas y altamente selectivas); y estudiantes de primer año de universidades docentes (privadas y no selectivas). Para lo anterior, se utilizó la tipología de universidades de José Joaquín Brunner (2009) ${ }^{4}$, invitando a estudiantes de los tipos de universidades más dispares, según el desarrollo de sus funciones (universidades del grupo 1, complejas de investigación versus universidades de los grupos 6 y 7 , solo docentes) y según los niveles de selectividad que aplican en sus procesos de admisión de estudiantes (universidades del grupo 1 , altamente selectivas versus universidades de los grupos 6 y 7 , no selectivas).

4 Brunner (2009) identifica para el caso chileno a nueve grupos de universidades, diferentes según su naturaleza, funciones, características y resultados. Se trata de las universidades de investigación (grupo 1), universidades regionales estatales (grupo 2), universidades regionales católicas (grupo 3), universidades relativamente especializadas (grupo 4), universidades privadas selectivas (grupo 5), universidades privadas de tamaño mayor, no selectivas (grupo 6), y universidades privadas de tamaño menor, no selectivas (grupo 7). 
Los focus group se realizaron en el mes de agosto de 2015. Participaron entre seis y hasta 10 estudiantes en cada uno de los grupos. Los participantes fueron reclutados de acuerdo con los criterios antes indicados, mediante la técnica de "bola de nieve" en redes sociales y con la ayuda de coordinadores en entidades educacionales. Las reuniones fueron dirigidas por un moderador, quien aplicó una pauta semiestructurada que abordó los siguientes temas:

- Percepciones generales respecto de la publicidad en educación superior y sus principales características (formales y de contenidos).

- Nociones de publicidad engañosa, su magnitud, características y principales ámbitos es los que se da.

- Opiniones respecto del examen de algunas piezas de publicidad seleccionadas.

- Conocimiento y opinión los estudiantes sobre la regulación de la publicidad, sus límites y los derechos que tienen al respecto.

Las técnicas de focus group se justifican por la efectividad en la obtención de percepciones en el área de interés de la investigación, en un contexto de conversación grupal guiada y flexible (Krueger y Casey, 2009).

\section{El problema de la publicidad engañosa. Alcances en la literatura}

\subsection{Cambios en educación superior y el contexto de la publicidad}

En el mundo, las dinámicas de mercantilización de la educación superior han traído diversas transformaciones y nuevas dinámicas, entre las que se cuenta el uso generalizado de prácticas de marketing y publicidad para el posicionamiento competitivo de las instituciones y atracción de estudiantes (Anctil, 2008; Brunner, 2004; HemsleyBrown y Oplatka, 2006; Jongbloed, 2003; Marginson, 2006).

En Chile, la reforma de 1980 transformó significativamente la educación superior, introduciendo las bases de un sistema que ha 
avanzado privilegiando lógicas de (cuasi) mercado como principal mecanismo de coordinación (Bernasconi, 1994; Brunner, 1997; Brunner, 2008b; Salazar y Leihy, 2013; Zapata et al., 2011). La excepcionalidad de la educación superior chilena incluye, entre sus características más sobresalientes, muy altos niveles de privatismo, desregulación y fuerte competencia entre instituciones (Brunner, 1993; Espinoza, 2005).

La competencia por estudiantes, recursos y prestigio impulsa a las instituciones a buscar las mejores maneras de posicionarse y diferenciarse, muchas veces, en desmedro de su misión y prioridades académicas (Bok, 2009; Kirp, 2004; Zemsky, Wegner, y Massy, 2005). En ausencia de los mecanismos tradicionales de coordinación de la educación superior, la coordinación de mercado se juega fundamentalmente por medio de transacciones entre proveedores y consumidores en competencia permanente (Clark, 1983). Este contexto ha generado nuevas dinámicas institucionales y la importación de modelos de gestión privados y del mundo de los negocios a la educación superior (Gibbs, 2007; Oplatka y HemsleyBrown, 2004).

Mientras el Estado presiona por mayor rendición de cuentas, dichos mecanismos no han traído necesariamente mayor transparencia al sistema (Trow, 1996). Más bien abundan los problemas de información, poco se sabe respecto de la calidad entre las instituciones y los estudiantes, y los usuarios del sistema quedan en una posición fuertemente asimétrica respecto de las instituciones (Brown, 2007; Dill, 1997; Zapata y Fleet, 2012). En este contexto, la publicidad engañosa aparece como un asunto complejo, que atenta contra la confianza y fe públicas, necesarias para el funcionamiento del sistema (Rhoades y Slaughter, 2004; Trow, 1996).

\subsection{La publicidad como información, persuasión y posicionamiento}

En el contexto descrito, la difusión de contenidos a través de publicidad se ha convertido en una de las estrategias importantes de transmisión de información, persuasión y atracción de estudiantes 
y posicionamiento por parte de las instituciones. Las presiones por darse a conocer, captar demanda, diferenciarse y fidelizar a ciertos nichos de estudiantes es cada vez mayor, según se incorporan mayores dinámicas de mercado en la industria de la educación superior (Brunner y Uribe, 2007).

La publicidad constituye una actividad en un contexto mayor de marketing y comunicaciones corporativas (Capriotti, 2009), y tiene por objeto informar y persuadir a los consumidores acerca de los beneficios de los bienes y servicios ofrecidos (Durandin, 1990; Noguero, 2007). Es, ante todo, un acto de comunicación a través de medios cada vez más dinámicos y flexibles. Por su parte, Durán (1982) sostiene que "la publicidad es un fenómeno a través del cual alguien intenta comunicar algo a un conjunto de personas, que llamaremos población objetivo, con objeto de persuadirles a actuar en un sentido determinado" (p. 17). La publicidad informa al consumidor de la existencia y propiedades de un producto o servicio, a la vez que se justifica en cuanto a su finalidad de influir en la conducta ajena en beneficio propio.

De uno u otro modo, para la publicidad es clave conocer a sus consumidores o usuarios y definir una estrategia de posicionamiento y presencia en un medio competitivo. Las organizaciones construyen la promesa por la cual buscarán distinguirse de sus competidores, usando para ello mensajes coherentes, consistentes y atractivos en el contexto de la actividad que se desarrollan (Semprini, 1995; Sevier, 2001). En efecto, la función básica de los contenidos de la publicidad es el logro del posicionamiento, identificación de cierto nicho y la diferenciación (Capriotti, 2009; Curubeto, 2007). Aquí, tanto los contenidos informativos como aquellos destinados a la persuasión (habitualmente de alto contenido simbólico) son parte del mensaje publicitario, cuestión que es comprendida y es parte de los patrones de consumo y de lo que busca el público.

La psicología y los estudios acerca de la cultura de masas han contribuido a explicar diversos patrones de consumo que han impactado en la manera en que se desarrolla la publicidad la que, en ocasiones, puede estar cargada de simbolismo y representaciones 
que son justamente el fundamento del consumo de las personas. El papel de la publicidad, según Ewen (2001) no sería solo informar y dar a conocer cierto producto, sino fundamentalmente hacer que sus consumidores potenciales se sientan parte de un grupo exclusivo, del cual antes eran excluidos, o bien, ignorados. Dicha dimensión opera en el orden de los deseos y la ficción. Asimismo, para algunos autores la publicidad juega con promesas y discursos que no necesariamente se anclan en beneficios funcionales de los productos y sus procesos de producción respectivos (Bigne, Andreu y Rodríguez, 2000). Lo anterior conlleva un problema potencial, en la medida en que la publicidad reduzca sus contenidos a una cantidad de información mínima, o bien, derechamente prescindiendo de ella y descansando en atributos puramente ficticios y simbólicos.

\subsection{Publicidad engañosa}

Gardner (1975) es uno de los primeros autores en abordar los abusos en materia de publicidad, ofreciendo una tipología que incluye mentiras inconscientes, discrepancias entre las aseveraciones y los hechos y distorsiones entre las aseveraciones y las creencias del destinatario. Según Russo, Metcaf y Stephens (1981) estas categorías corresponden, en términos generales, a fraude, falsedad y engaño, respectivamente. En lo que se refiere a la publicidad engañosa propiamente tal. Hastak y Mazis (2011) distinguen cinco tipos específicos: omisión de hechos materiales, engaño a través de confusión semántica, engaño intraatributo, engaño interatributo y engaño basado en fuentes.

Desde un punto de vista práctico, la clave para poder calificar cierta publicidad como "engañosa", pasa por determinar cuáles son los elementos a juzgar y que podrían contener elementos de engaño como los antes indicados. A juicio de los autores, en el campo de la educación superior los elementos clave se refieren a la naturaleza del servicio, siendo particularmente importantes su disponibilidad, precio o cantidad, resultados o identidad y méritos del anunciante. Schoenmakers (2000) analiza los componentes que habitualmente son considerados y los mecanismos de reclamación en la regulación internacional en países como Reino Unido, Suecia, Finlandia, Austria, 
Países Bajos, Luxemburgo, Irlanda, Francia, Dinamarca, Bélgica, Grecia, Alemania, España, Italia Portugal y Estados Unidos. Se trata de experiencias que se han ido generando a partir del establecimiento de tratados (especialmente en el caso de la Unión Europea) y que han impulsado iniciativas específicas en los países. La directiva del Parlamento Europeo define publicidad engañosa como

(...) toda publicidad que, de una manera cualquiera, incluida su presentación, induce a error o puede inducir a error a las personas a las que se dirige o afecta y que, debido a su carácter engañoso, puede afectar su comportamiento económico o que, por estas razones, perjudica o es capaz de perjudicar a un competidor.

Para el Parlamento Europeo, constituye una práctica comercial desleal aquella que distorsiona o puede distorsionar de manera sustancial, con respecto al producto de que se trate, el comportamiento económico del consumidor medio al que afecta o al que se dirige la práctica (Soto, 2010).

Por una parte, la publicidad cumple importantes funciones al promover competencia, mantener los precios bajos, establecer presiones por mejorar la calidad de los productos y servicios, mantener altas expectativas por parte de los consumidores, etc. Por otra, la mantención del orden requiere del establecimiento de poder político en los consumidores (Rao, 1998). Consumidores bien informados, exigentes y organizados alzan los estándares de la publicidad y presionan sobre la responsabilidad de los proveedores. Las organizaciones de consumidores, por lo general promovidas desde el gobierno, se expanden con velocidad en parte importante del mundo desarrollado como mecanismos ciudadanos de empoderamiento, destinados a frenar los abusos y malas prácticas comerciales (Mayer, 1989).

Es importante también tener presente ciertas regulaciones de orden profesional y que provienen de las convenciones y ética de la industria publicitaria, recogida a veces en ciertos cuerpos legales (en los tratados de la Unión Europea, por ejemplo). Se trata de principios aplicables al ejercicio de la publicidad, tales como la legalidad 
publicitaria (acogerse estrictamente a la ley) y responsabilidad social (ajuste al buen gusto, decoro social, moralidad y buenas costumbres), el principio de la honestidad, el de la confiabilidad o autenticidad, y el de la lealtad publicitaria (Schoenmakers, 2000). Estos principios promueven buenas prácticas en el ejercicio de la publicidad, estableciendo criterios para juzgarla en cuanto a su contenido (Soto, 2010).

\subsection{Publicidad y educación superior}

A nivel internacional existen pocas referencias respecto de la publicidad en educación superior, siendo escasos aún los esfuerzos por vincular la literatura relativa a la publicidad y al marketing con la de la educación superior (especialmente aquella referida al funcionamiento de mecanismos de coordinación de mercado). Según HemsleyBrown y Oplatka (2006), parte importante de los estudios empíricos relativos a la publicidad en educación superior han abordado el tema tomando como referencia conceptos y teorías de marketing, sin incluir modelos teóricos propios de la educación superior. En este sentido, se trata de un campo de estudio incipiente, pero de creciente interés e importancia en sistemas también crecientemente más masificados, diversos y competitivos.

Los esfuerzos por conectar ambas literaturas (Anctil, 2008) dan cuenta de ciertas particularidades que adquiere la publicidad y difusión de información en el contexto de este sector, principalmente debido al tipo de misión institucional que estas exhiben (la cual generalmente no es del tipo empresarial) y a las características del servicio ofrecido (experiencias de aprendizaje intangibles). Por su parte, existe bastante literatura que discute el carácter de la actividad publicitaria y su tensión entre los fines comerciales y la perversión del fin primero de la educación (Gibbs, 2007; Kittle, 2000). Por una parte, el marketing en educación se ha vuelto imprescindible y por otra, tratar a la educación como un commodity resulta problemático, toda vez que constituye un bien público y no uno de consumo (Maringe y Gibbs, 2008).

Con todo, se trata de un tema que ciertamente ha crecido en su nivel de importancia. La publicidad ha sido cada vez más 
relevante dentro del presupuesto de instituciones académicas, lo que ha producido una evolución tanto en la forma como en el contenido de la misma (Kittle, 2000). Es importante reconocer que a medida que la industria de instituciones superiores crece, más aparece el tema de la integridad académica y su proliferación ha provocado también un aumento en los casos de irregularidades a nivel de mercado (Macfarlane, Zhang y Pun, 2014). Las instituciones de educación superior han llegado a operar, cada vez más (bajo la presión gubernamental), como si fueran empresas que compiten para vender sus productos a los consumidores (Fairclough, 1993).

Acerca de los contenidos de la publicidad, existen algunos estudios, aunque no abundan. Askehave (2007) sugiere que las universidades construyen su imagen para impactar en los potenciales estudiantes, comunicando su identidad a través de mucha retórica en sus textos e imágenes. Briggs (2006) ha estudiado el conjunto de factores que influencian la selección de universidad de los estudiantes, planteando en consecuencia el tipo de discursos que por lo general cubre la información y publicidad de las mismas. En particular, hay factores críticos que influyen en la selección de universidades de los estudiantes potenciales y que dependen del tipo de instituciones, aunque cubren por lo general los costos de los paquetes universitarios (Briggs y Wilson, 2007).

Otros autores han observado el conjunto muy amplio de audiencias que tienen las instituciones de educación superior y que, por lo mismo, influyen en su publicidad. Constantinides y Zinck Stagno (2011) sostienen, por su parte, que el marketing universitario se construye sobre la base de tres grupos de consumidores: egresados, estudiantes y postulantes, los que es preciso separar puesto que sus objetivos varían. El desarrollo de las "marcas" institucionales se puede apreciar tanto a través de canales formales (su publicidad y papelería), como informales (ya sea a través de eventos deportivos, medios institucionales u otros), cubriendo así los distintos tipos de públicos mediante mensajes variados (Kittle, 2000).

En relación con la publicidad engañosa en educación superior, la literatura es prácticamente inexistente. Un ejemplo es un estudio 
de Bradley (2013), que ofrece nueve tipos de información errónea en el marketing de universidades (en sus prospectos): la omisión de los hechos e información selectiva, la redacción engañosa, las interferencias engañosas sobre un atributo, las asociaciones engañosas entre atributos, las menciones engañosas, las discrepancias en hechos, las falsedades, la elaboración de comparaciones inadecuadas y las reclamaciones sin punto de referencia. En este sentido, resulta clave para juzgar algo como engañoso en el campo de la educación superior cuando existen antecedentes que conducen a error o distorsionan la naturaleza del servicio que se ofrece, lo que podría expresarse en cuanto a su disponibilidad, precio o cantidad, como respecto de los resultados o la promesa a la que conduce, o bien, respecto de la identidad y méritos de la institución que la ofrece.

En el último tiempo ha crecido el interés por entender la publicidad en un contexto mayor, el de los medios sociales. Al respecto, así como ha ocurrido en diversas industrias, Constantinides y Zinck Stagno (2011) plantean que también el marketing en social media se ha expandido fuertemente en el sector de la educación. Se trata en particular de comunicaciones integradas de marketing por parte de las universidades, que rompen con los paradigmas tradicionales de unilateralidad y unidireccionalidad de las comunicaciones (EdmistonStrasser, 2009).

Como ya se ha indicado, en Chile prácticamente no existe investigación respecto de la publicidad en educación superior. En los pocos estudios disponibles, se reporta un gasto excesivo en términos internacionales comparados, demasiado alto comparado con otros sectores productivos del país, desproporcionado en el caso de ciertos tipos de instituciones y, en términos generales, irracional desde el punto de vista de las prioridades de inversión académica que el país requiere. Brunner (2004) estima que las instituciones destinan en publicidad en medios tradicionales casi un $2 \%$ del gasto total en educación superior del sistema, lo que equivale a US\$150 por estudiante nuevo matriculado en el sistema al año 2003. También se ha sostenido que el gasto en publicidad de instituciones de educación superior es excesivamente alto, comparado con otras industrias, alcanzando en varias oportunidades un tercer lugar luego 
de las industrias del retail y la telefonía (Monckeberg, 2011). Worner y Santander (2012) identifican enormes diferencias en el gasto en publicidad entre tipos de universidades, siendo las universidades docentes no selectivas aquellas que gastan considerablemente más que el resto del sector (sobre un 5\% de su presupuesto).

\section{Regulación de la publicidad engañosa en Chile}

El concepto de publicidad engañosa está ciertamente recogido en la legislación chilena, aunque no se encontró consenso en la opinión de los especialistas y abogados consultados de si se trata de un concepto claramente definido o no. Mientras que para algunos no existe una definición jurídica suficientemente clara, para otros, el problema no está en la definición de la ley, sino que en el orden procesal.

\subsection{Principales cuerpos normativos}

La publicidad engañosa en Chile (más allá de si se refiere a sus componentes de fraude, falsedad o engaño) tiene por antecedentes generales lo establecido en el Código Civil y de Comercio. El Código Civil regula la conformación del consentimiento entre las partes, estableciendo la figura del engaño como un elemento de vicio o error para el establecimiento del consentimiento. En este sentido, la publicidad engañosa se puede entender como un antecedente para declarar nulo un contrato en el que no ha existido un debido consentimiento entre las partes. Por otro lado, el Código de Comercio regula la naturaleza y funcionamiento de los contratos de adhesión, aplicados por lo general a la relación entre instituciones de educación superior y las personas. En este sentido, el contenido de la publicidad de las instituciones configura parte de la información proporcionada por el vendedor, por lo que se debiera entender como parte integral de los términos del contrato de adhesión entre las partes.

La Ley del Consumidor (Ley No 19.496, 1997), considerada por algunos como "el nuevo código civil", define términos ciertamente más estrictos para regular a los proveedores y proteger a los consumidores. Establece estándares más altos en la relación entre las partes, sancionando los casos de publicidad engañosa, cuando se induce 
a error o engaño sobre las características del bien o servicio que se ofrece y exigiendo que los anuncios sean comprobables. Existen varios aspectos que deben ser informados y que en caso contrario podrían conducir a sanciones económicas con cargo fiscal.

La ley establece una definición de publicidad engañosa, que se refiere a "cualquier mensaje publicitario que induzca a error o engaño" (Ley No 19.496, 1997). El error o engaño en la publicidad puede verificarse en varios aspectos: los componentes del producto; la idoneidad del bien o servicio para los fines que se pretende satisfacer; las características relevantes del bien o servicio; el precio y su forma de pago y el costo de los créditos, cuando existan; las condiciones de la garantía; y su condición de no producir daño al medioambiente o a la calidad de vida ${ }^{5}$ (Ley No 19.496, 1997).

La publicidad es definida como:

(...) la comunicación que el proveedor dirige al público por cualquier medio idóneo al efecto, para informarlo y motivarlo a adquirir o contratar un bien o servicio, entendiéndose incorporadas al contrato las condiciones objetivas contenidas en la publicidad hasta el momento de celebrar el contrato (art. 1, Ley $\mathrm{N}^{\circ}$ 19.496).

Para que la publicidad sea válida, la ley establece que debe cumplir con ciertos criterios básicos, que incluyen su veracidad y posibilidad de ser comprobada. No pueden señalar atributos que el servicio no entregue. Las afirmaciones publicitarias deben ser verificables en cuanto a la promesa contenida en ella. También debe ser oportuna, completa y relevante para que el consumidor cuente con los datos necesarios para adoptar su decisión. Finalmente, debe ser respetuosa de las reglas del juego y su contenido forma parte de las condiciones del contrato.

La Ley del Consumidor establece multas con cargo fiscal para los infractores (art. 24). Asimismo, le otorga al Servicio Nacional del Consumidor (Sernac) atribuciones para realizar estudios, informar

5 Síntesis personal del artículo 28. 
y educar a los consumidores, mediar en reclamos y hacerse parte en causas frente a la justicia. Finalmente, la ley reconoce a las organizaciones de consumidores como entidades de representación individual y colectiva ante la justicia, y promueve su funcionamiento a través de un fondo concursable de financiamiento (Engel, 1998). La regulación de protección a los consumidores ha sido criticada por sus limitaciones, especialmente debido a las debilidades en materias de acciones colectivas y a la "escuálida reglamentación en materia publicitaria” (Fernández, 2005, p. 115). Actualmente se está tramitando un proyecto de fortalecimiento del Sernac (Presidencia de la República, 2014), destinado a otorgarle mayores facultades de fiscalización y sanciones, así también como para promover la organización y el financiamiento de organizaciones de consumidores.

La Ley del Consumidor contiene también cláusulas específicas respecto de los servicios educacionales, que son muy relevantes en esta materia. En particular, establece el derecho a retracto y devolución de los pagos y documentación de pagos en instituciones de educación superior, en los casos donde el estudiante desista de matricularse (art. 3). Sin embargo, se trata de un derecho fuertemente restringido y que solo puede ser ejercido hasta 10 días después de publicados los resultados de las postulaciones a las universidades del Consejo de Rectores de las Universidades Chilenas, CRUCH.

Por último, es importante mencionar cierta normativa no jurídica y que ha sido levantada por la industria de la publicidad, las asociaciones de medios y agencias de publicidad. A través del Consejo de Autorregulación y Ética Publicitaria, Conar, se promueven mecanismos de autorregulación y se ha elaborado un código de ética y procedimientos de reclamación para normar -de forma voluntariala actividad publicitaria nacional. Aunque no hay casos de reclamos en materia de educación superior, la experiencia de Conar ha sido valiosa para levantar principios éticos en publicidad y comprender que la regulación en ciertos sectores requiere de normas específicas levantadas por los propios especialistas del campo profesional que se trate. 


\subsection{Organismos responsables en educación superior}

Existen también otros cuerpos legales particulares en educación superior y que establecen funciones de regulación y atribuciones de evaluación y fiscalización a organismos del Estado que pueden intervenir en casos de publicidad engañosa.

Al Ministerio de Educación le corresponde, por ejemplo, velar por el cumplimiento de las normas legales y reglamentarias que regulan la educación superior, para lo cual se relaciona con las instituciones de educación superior, pudiendo solicitarles información y procesar reclamos. Consultados acerca de los casos de publicidad engañosa en el último tiempo, se planteó que han existido cuestiones de universidades que hicieron publicidad sin contar con el reconocimiento oficial, o bien, casos de reclamos de estudiantes sobre publicidad que no se condicen con la realidad y que han sido tramitados con la autoridad correspondiente. Aunque las atribuciones del ministerio son limitadas en esta materia, la Ley $N^{\circ} 20.800$ de Administrador Provisional y Cierre de Instituciones de Educación Superior (de 2014), le otorgó facultades adicionales para solicitar información y fiscalizar a las instituciones en casos de que caigan en incumplimientos financieros o académicos, o en infracciones graves a sus estatutos.

El CNED (Ley No 20.370) tiene por función la administración del sistema de licenciamiento de nuevas instituciones de educación superior, correspondiéndole pronunciarse respecto de los proyectos institucionales y verificar su desarrollo y cumplimiento de acuerdo con la ley. Para lo anterior, cuenta con criterios de evaluación que consideran la publicidad de las instituciones y su integridad institucional. Consultados respecto de casos de publicidad engañosa, se planteó que aunque es una materia que se revisa, no han existido observaciones puntuales en el último tiempo a las instituciones en licenciamiento. Sin embargo, sí ha habido situaciones de observaciones a la integridad y oportunidad de la información que entregan las instituciones. Asimismo, este consejo mantiene un monitoreo de la prensa e información pública del medio, recibiendo también reclamos de usuarios del sistema que tramita con la autoridad correspondiente. Es parte de la misión del CNED educar y promover la información al 
público, manteniendo para ello sistemas de información, estadísticas y estudios sobre el sistema de educación superior, contribuyendo así a una mayor transparencia.

Finalmente, la Comisión Nacional de Acreditación (Ley $\left.\mathrm{N}^{0} 20.129,2006\right)$ tiene por función la verificación y promoción de la calidad de la educación superior, llevando a cabo procesos de acreditación institucional y de programas. La CNA mantiene permanentemente un sistema de revisión de la publicidad de las instituciones respecto de los procesos y resultados de la acreditación institucional y de programas. Para ello, cuenta con normas específicas (Circular 19, CNA-Chile) e información pública respecto del estado de las observaciones planteadas a las instituciones. Consultados sobre casos específicos de publicidad engañosa, se planteó que existen situaciones de no cumplimiento de la normativa sobre información de la acreditación, pero que sin embargo es habitual que las instituciones, una vez advertidas sobre los problemas, rápidamente corrijan su publicidad. Aunque la CNA también recibe reclamos de estudiantes, no se informó de la existencia de casos asociados a publicidad engañosa propiamente tal.

\subsection{Casuística}

Las cortes de justicia han conocido varias demandas (individuales y colectivas) que acusan de publicidad engañosa de universidades chilenas. Las más importantes, por su exposición pública y avance en su tramitación, han involucrado a las universidades del Mar (causas iniciadas en 2007 y 2013), Tecnológica Metropolitana (tres causas iniciadas en 2007), de Ciencias de la Informática (2009) y Santo Tomás $(2012)^{6}$. De estos procesos, dos están cerrados y solo uno finalizó con una sentencia que castigó a una universidad por publicidad engañosa ${ }^{7}$. El resto de los procesos, en cambio, está todavía en tramitación, con diversos niveles de avance y resultados preliminares dispares.

6 Adicionalmente, se registran causas por publicidad engañosa que involucran a los institutos profesionales Santo Tomás (2009) y del Valle Central (2009) y al centro de formación técnica Simón Bolívar (2012).

7 Aunque luego se generó un avenimiento entre las partes, aprobado en tribunales. 
A juicio de los especialistas consultados en este estudio, la tramitación por causas de publicidad engañosa en Chile es compleja por varias razones. En principio, debe contarse con clara evidencia del carácter engañoso o erróneo de la publicidad de la institución (la prueba respecto de la falta de campo profesional en el escándalo de las carreras de ciencias criminalistas en el año 2007, por ejemplo). Es ciertamente difícil establecer "dolo" en estos casos, esto es, probar que ha existido un intento deliberado de engañar. Las multas asociadas a publicidad engañosa son relativamente bajas, especialmente cuando no hay reiteración ni engaño premeditado. Por su parte, las multas son con cargo fiscal, no existiendo incentivos relevantes para la demanda (salvo las indemnizaciones, cuando logran ser establecidas, y pago de costes, una vez finalizado el proceso). Es difícil probar daños y perjuicios muy significativos, por lo que las indemnizaciones a las que podrían acceder los demandantes son por lo habitual relativamente bajas (sumado a la pérdida de tiempo, molestias, etc.). Aunque se puedan probar los daños y perjuicios, la tramitación de una demanda hace mayor sentido cuando es colectiva que cuando es individual, por su carga de tiempo y recursos. También es importante considerar que es difícil para un estudiante demandar a su institución cuando tiene procesos académicos en curso. En cambio, parece más sencillo exigir el cumplimiento de los contratos existentes, o bien, reclamar ante la justicia por la causal de incumplimiento de contrato. En suma, aunque por primera vez en Chile se están comenzando a conocer casos de demandas por publicidad engañosa de universidades, se trata más bien de casos muy excepcionales, asociados a grandes escándalos en el medio. La impresión es que, no obstante lo anterior, existen varias circunstancias que desincentivan a los usuarios a reclamar por publicidad engañosa en la justicia.

\section{El caso de la publicidad en prensa escrita: análisis empírico}

De acuerdo con el trabajo de campo, durante el periodo comprendido entre el 1 de noviembre de 2014 y el 31 de marzo de 2015, las universidades chilenas publicaron un total de 4.614 avisos publicitarios en prensa escrita (diarios y revistas de circulación nacional y regional). Dicha cantidad constituye la muestra de piezas 
de publicidad levantada por este estudio y sobre la cual se realizó el análisis descriptivo. A continuación se sintetizan algunas de las características más destacables, tendencias y regularidades entre las universidades estudiadas.

\subsection{Presencia en medios escritos de la publicidad de universidades}

La publicidad de las universidades se concentra en los últimos y primeros meses de cada año, lo que coincide con los periodos de postulaciones y admisión a la educación superior. De la información recogida para el año 2014-2015, se observó un promedio de 30,6 avisos diarios durante el periodo estudiado: en los meses de diciembre de 2014 y enero de 2015, el promedio de avisos fue de 40,7 y 37,8 respectivamente, y durante los meses de noviembre de 2014, febrero y marzo de 2015 el promedio fue de 27, 19,2 y 26,9 avisos.

Durante el periodo de estudio hubo dos días cuando el número de piezas publicitarias prácticamente se cuadriplicó respecto de la media de avisos diarios. Se trata de los días 28 de diciembre de 2014 y 11 de enero de 2015, fechas que coinciden con la publicación de resultados de la Prueba de Selección Universitaria (PSU) y la de los resultados de las postulaciones al sistema de admisión del CRUCH.

Las diferencias de circulación de diarios y la variación del número de lectores durante la semana, se expresa también en las diferencias en el número de avisos publicados durante los días hábiles (de lunes a viernes), donde se constatan 28,2 avisos por día, en promedio, y durante los fines de semana (sábado y domingo), donde sube a 36,3 avisos diarios en promedio.

La presencia de avisaje publicitario de las universidades se distribuye desigualmente entre los medios de comunicación escritos. Se constató que estas publicitan preferentemente en diarios (96,4\% del total de los avisos) más que en revistas (en las que se contabilizó un 3,6\%), muy proporcionalmente a la manera en la que se distribuye también la circulación entre dichos tipos de medios en el país. Por su parte, del total de la publicidad, se observó una significativa presencia en diarios de circulación regional (57,6\%), lo que contrasta con 
una relativa menor presencia en diarios nacionales $(21,2 \%)$, diarios gratuitos metropolitanos $(16,1 \%)$ y los diarios nacionales financieros $(1,6 \%)$.

Aunque la publicidad contabilizada mediante el número de avisos da una buena idea de la magnitud de la difusión en prensa escrita, es importante examinar también el tamaño de las piezas, el que varía considerablemente y permite una mejor apreciación de la presencia de la publicidad. Al respecto, el tamaño total del avisaje de las universidades chilenas durante los cuatro meses estudiados alcanza a $2.163 .120 \mathrm{~cm}^{2}$.

Analizada la publicidad de las universidades por tamaño, la distribución por tipos de medios cambia. La presencia en medios regionales baja a menos de un 50\% y los diarios de circulación nacional suben a un $27,7 \%$. En efecto, muchas universidades privilegian inserciones de gran tamaño (a veces de página completa) en los medios nacionales (El Mercurio, La Tercera, Las Últimas Noticias, La Cuarta y La Segunda), especialmente durante los fines de semana.

\subsection{Diferencias entre universidades}

El estudio identificó importantes diferencias en la presencia de publicidad entre las universidades chilenas. En principio, de las 60 universidades existentes al año 2014, cinco no registraron presencia alguna durante el periodo de estudio. Salvo una, las universidades que no presentaron publicidad son instituciones no acreditadas ${ }^{8}$. Por otra parte, existe un puñado de instituciones que destaca por contar con gran presencia publicitaria en los medios escritos. Se trata de universidades de gran tamaño y que operan como corporaciones o redes de instituciones, en su mayoría pertenecientes a la categoría de universidades privadas docentes masivas no selectivas (grupo 6, según Brunner, 2009). En términos del número de piezas, destacan tres universidades ${ }^{9}$, las que en conjunto representan un $32,7 \%$ del

8 Se trata de la Universidad de Artes y Ciencias Sociales ARCIS; la Universidad Miguel de Cervantes; la Universidad Adventista de Chile; la Universidad Los Leones; y la Universidad Metropolitana de Ciencias de la Educación (UMCE).

9 Santo Tomás, Inacap y Universidad Andrés Bello. 
total de avisos en el periodo. Entre ellas, existen dos corporaciones ${ }^{10}$, cuya publicidad usualmente no distingue entre los diferentes niveles de educación superior en los que imparten educación (universidad, instituto profesional y centro de formación técnica). Si se considera la superficie de avisaje, destacan las mismas tres instituciones más una cuarta $^{11}$, representando en conjunto el $43 \%$ del avisaje.

Para los efectos de comparar la cantidad de publicidad según el tipo de universidad, se realizaron comparaciones utilizando la tipología de Brunner (2009) y según su naturaleza jurídica y calidad (medida por años de acreditación a diciembre de 2015). Agrupadas de estos dos últimos modos, se constataron diferencias relevantes en la presencia de publicidad entre las universidades chilenas.

Como puede observarse en la Ilustración 1, las universidades pertenecientes al $\mathrm{CRUCH}$, tanto las estatales como las privadas, que representan un $22 \%$ y $17 \%$ de la matrícula del sistema respectivamente, aparecen con una proporción considerablemente más baja de publicidad que las universidades privadas creadas con posterioridad al año 1981. En este sentido, las universidades privadas que están fuera del CRUCH y que representan al año 2014 un 61\% de la matrícula, registraron una presencia de publicidad de más de un $70 \%$, medida por número de avisos. Estas universidades registraron más de 3/4 del total de la superficie de publicidad universitaria en medios escritos.

10 Inacap y Santo Tomás, que en conjunto representan el 17\% de la matrícula de educación superior al año 2014.

11 Universidad Autónoma de Chile. 
Ilustración 1. Piezas publicitarias por tipo de institución (según naturaleza jurídica).

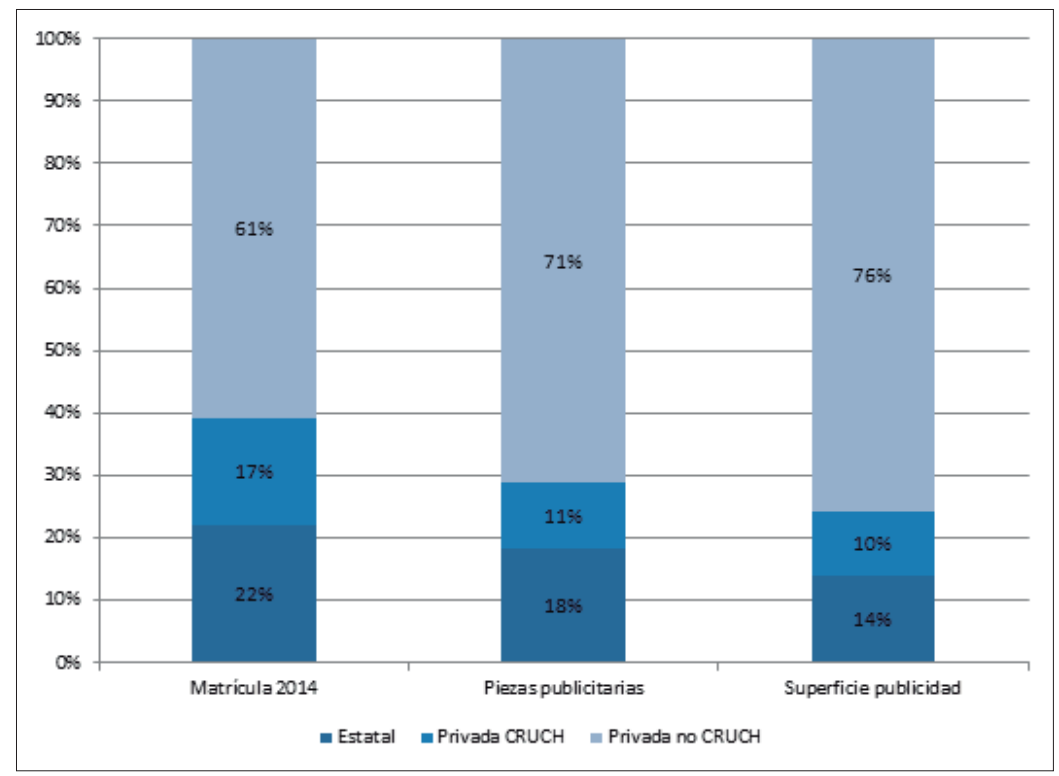

La distribución de la publicidad según años de acreditación muestra también diferencias importantes (Ilustración 2). Es así como aquellas universidades no acreditadas o bien con una relativamente baja acreditación (segmento de 2-3 años), están sobrerrepresentadas en términos de cantidad de avisos y superficie de su publicidad respecto de su participación en la matrícula. Mientras que suman un $41 \%$ de la matrícula de 2014, representan el 56\% del número de avisos y el 54\% de la superficie. Contrariamente, aquellas universidades con mayor acreditación (segmentos 4-5 y 6-7), están subrepresentadas en cuanto a su presencia en publicidad. En suma, se aprecia una relación inversa entre calidad y publicidad en medios escritos. Esta evidencia es consistente con los datos aportados por Worner y Santander (2012), quienes mostraron cómo las universidades de menor calidad gastaban proporcionalmente más en publicidad. La presente investigación agrega, además, que es posible identificar a un grupo minoritario de universidades (en este caso, algunas privadas docentes, masivas y no selectivas: grupo 6, según Brunner 2009) cuya presencia publicitaria en medios tradicionales es desproporcionadamente más agresiva que cualquier otra combinación de instituciones del sistema. 
Ilustración 2. Piezas publicitarias por tipo de institución Isegún años de acreditación)

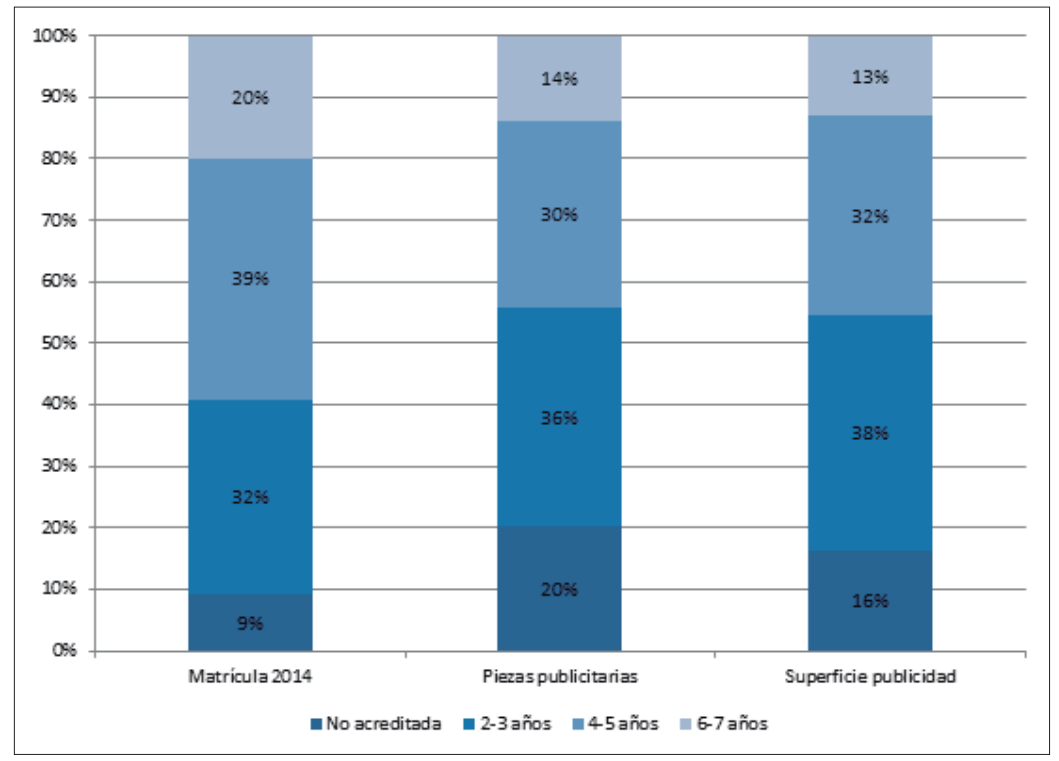

\subsection{Contenidos de la publicidad}

Respecto de los contenidos de la publicidad, este estudio ha acumulado abundante información, no obstante, aquí apenas se mencionan algunos antecedentes de tipo descriptivo general.

En su gran mayoría, la publicidad de las universidades chilenas levantada durante el periodo de estudio de este proyecto se refiere fundamentalmente a la oferta académica de pregrado. Así, un 76\% de las piezas de publicidad tenidas a la vista ofrece información respecto de las bondades de los programas ofrecidos, sus facultades e instituciones a los que pertenecen. Una proporción considerablemente menor es la que se refiere a la oferta de posgrado (un 15,8\%, en su mayoría de universidades de investigación y complejas, del grupo 1 de la clasificación de Brunner, 2009). El 8,2\% restante consiste en avisaje de otras actividades de las instituciones, como seminarios, cursos de verano, actividades de extensión, etc.

La estrategia y niveles de complejidad de las campañas publicitarias entre las universidades difieren significativamente. 
Mientras algunas repiten un par de avisos institucionales durante todo el periodo, otras realizan complejas combinaciones de textos, colores y mensajes, que van variando en el tiempo y que prácticamente no se repiten nunca entre sí. En algunas universidades se observa una centralización del emisor (es siempre la universidad, en su conjunto), en otras (usualmente en algunas universidades pertenecientes al CRUCH) hay variedad de emisores, como facultades, centros de investigación, programas, sedes.

Hay elementos muy recurrentes en la publicidad de las universidades chilenas. Predomina el uso del color, que muchas veces mantiene patrones institucionales. Las publicaciones en blanco y negro son escasas (16,8\%) y en gran medida (un $80 \%$ de estas) corresponden a avisaje de programas de posgrado.

El uso de imágenes es frecuente (un 65\% de las piezas), a la vez que bastante rudimentario en el común de las instituciones, con un bajo desarrollo de la dimensión "simbólica" y frecuentes inconsistencias con el mensaje y textos de las piezas. Entre las piezas con imágenes, abunda el uso de estudiantes (en un 43\% de los avisos, ya sea estudiando-trabajando o posando); la infraestructura de las universidades (un 20\% muestra fachadas, casas centrales o lugares específicos que forman parte de la identidad de la casa de estudio); y, en menor medida, egresados o trabajadores (identificados con las indumentarias o herramientas propias de sus oficios, en un $7 \%$ de los avisos). Hay una baja presencia de académicos y/o autoridades universitarias (en un 5\% y 1\% de las piezas con avisos, respectivamente).

La publicidad analizada utiliza principalmente imágenes de personas que responden a estereotipos que apelan a la construcción de una identidad relacionada más con las carreras en específico que con las instituciones en general. En este sentido, se trata de estudiantes que presumiblemente podrían pertenecer a cualquier institución, equilibrándose aspectos de género, vestimenta o rasgos físicos. Prácticamente no existe una identificación de tipos de estudiantes con ciertas universidades, salvo ocasionalmente en el caso de estudiantes adultos en instituciones y programas destinados 
a alumnos trabajadores, en los que se muestra a alumnos con familia o con vestimenta/ambiente vinculado con su lugar de trabajo.

En los casos en que las publicaciones no cuentan con imágenes, se destacan los encabezados en su mayoría con nombres de carreras o programas, y se potencia el impacto con el uso de colores institucionales.

La mayoría de las publicaciones de las universidades (un $94,5 \%)$ lleva su logo institucional, siendo una práctica usual su ubicación en la parte superior o alguna de las esquinas de la pieza publicitaria. Por lo general, el uso de logo no se destaca mucho en relación con el texto u otras imágenes utilizadas; sin embargo, aporta la identidad visual necesaria para que el receptor determine quién es el avisador.

En general, se utilizan avisos con múltiples encabezados, por lo que no siempre es fácil determinar el orden de la información que se transmite. En el caso de las universidades cuyas campañas publicitarias son más modestas (esto es, que tienen poco avisaje y escasamente diverso), por lo general, no hay un patrón en el diseño reconocible.

En cambio, en aquellas universidades con mayor publicidad, se hace evidente la existencia de un diseño de campaña propiamente tal. Por lo general, hay una identidad visual, que incluso con las variaciones que puedan tener (mayor o menor preponderancia de imágenes, por ejemplo), es evidente que se trata de una misma institución. Siguiendo esta línea, generalmente se trabaja conjugando de distintas formas las imágenes y la distribución de la información, rotando contenidos en avisos con distintos tipos de información. En ocasiones, se aprecian algunos diseños alternativos, aunque armónicos, cuyos contenidos se van alternando en el avisaje publicitado a lo largo del periodo de estudio.

Se observaron algunas excepciones cuando existe diversidad del emisor, esto es, cuando la universidad es publicitada centralmente y alterna programas, facultades y otras unidades académicas. En estos casos, asociados a universidades complejas y de gran tamaño, 
la diversidad de diseños y variedad de imágenes es importante. No existe necesariamente una línea clara de uso de colores, diagramación o mensajes, salvo por el uso del logo, que se encuentra razonablemente estandarizado en las diferentes piezas de publicidad institucional.

En general, la publicidad de las universidades analizadas cumple con la norma de acreditación, informando la situación de acreditación institucional, los años por los cuales les fue otorgada, las áreas, e incorporan el logo de la CNA. Aun cuando es ampliamente cumplida la norma de información acerca de acreditación institucional no lo es, sin embargo, la información respecto de la acreditación de programas. En efecto, se encontraron pocas piezas de publicidad en las que se reporta la información de acreditación de las carreras, incluso tratándose de publicidad directamente asociada con la oferta de carreras específicas de las instituciones.

En la mayoría de las publicaciones, la información de la acreditación no es destacada, sino que más bien cumple con la normativa básica. Por lo general, se sitúa en la sección inferior del aviso, sin ningún color distinto al predominante en la pieza que destaque el logo de la CNA. Aun cuando la normativa no tiene un diseño preestablecido que cumplir, la gran mayoría de las universidades ha ido adoptando un diseño muy parecido entre sí, en el que se consigna el logo de la CNA y a su lado la información de "acreditada" (o no), las áreas, años y fecha (desde y hasta). Se encontraron algunos pocos casos donde las universidades no cumplen con la norma, al omitir parte de la información referente a la acreditación. Sin embargo, se trata de excepciones. Cabe destacar que en la publicidad asociada a seminarios, cursos de extensión, congresos, etc., que algunas universidades utilizan frecuentemente como modo de difusión, es bastante común (en la mitad de las piezas, aproximadamente) que no se informe respecto de la situación de acreditación institucional.

En un 15\% de las piezas publicitarias se resalta la información sobre acreditación; esto es, que además del logo y la información habitual, se incluye alguna imagen o texto de tamaño importante acerca de su condición de acreditación y los años que tiene. En 
ocasiones, esto se acompaña de alguna información adicional respecto de certificaciones internacionales o de otras redes especializadas. Las universidades que cuentan con certificaciones adicionales a la acreditación nacional generalmente destacan ampliamente dicha condición. Finalmente, existen algunas piezas de publicidad (poco más de un 4\%) que reportan pertenencia de las universidades a otras organizaciones, principalmente al G9, CUECH y/o CRUCH ${ }^{12}$.

De la revisión de la publicidad realizada, se aprecian al menos tres tipos de mensajes muy recurrentes. En primer lugar, se constata el uso de una variedad de mensajes de tipo aspiracional, esto es, relativos a las oportunidades y desarrollo de un futuro exitoso, donde la superación personal es tomada como un elemento clave. En un segundo orden de importancia, se observan diversos mensajes de orden económico, los que hacen referencia a descuentos, becas y facilidades de pago de los estudios ofrecidos. Un tercer tipo de mensajes recurrentes, se refiere a las contribuciones de la universidad a su entorno social o nacional, mediante una variedad de actividades que va desde la investigación, extensión o derechamente a la formación de profesionales con cierto perfil.

Estos tres tipos de mensajes aparecen en parte importante del avisaje de las universidades analizadas. Son mensajes recurrentes que repiten diversos eslóganes, citas de personalidades, referencias a la misión institucional, o estadísticas que dan cuenta de las oportunidades de desarrollo profesional, económico o impacto social que se alcanza en las universidades.

Respecto de los principales atributos, se observan avisos principalmente de orden racional, esto es, que utilizan elementos como la oferta académica, empleabilidad y beneficios económicos (usualmente reforzados con números y porcentajes favorables de la institución), como argumentos para la oferta. El "llamado" es, por lo general, a "matricularse" en la universidad y en alguna de sus sedes

12 El G9, o grupo de las 9, reúne a las universidades privadas con financiamiento público directo, pertenecientes al Consejo de Rectores de las Universidades Chilenas, CRUCH. El CUECH corresponde al Consorcio de Universidades del Estado de Chile, que agrupa a las 16 (y ahora 18) universidades estatales. Todas las anteriores integran el CRUCH. 
y/o programas, respecto de los cuales la información proporcionada es presentada como atributos objetivos de lo que se ofrece.

Como se indicó anteriormente, hay variados acentos en los mensajes prevalentes de la publicidad, en sintonía con los atributos con los que contarían las instituciones. De este modo, aquellos especialmente reforzados tienen que ver con la calidad de las instituciones (sobre la base de porcentajes relacionados con la calidad docente, cantidad de egresados, actividades extracurriculares de las instituciones, etc.), la cantidad de beneficios económicos otorgados (becas, descuentos, créditos y otros beneficios) y algunos casos con indicadores de impacto respecto de los resultados logrados por la universidad (en el desarrollo local, investigación realizada, perfil de los egresados, etc.).

Cabe destacar que respecto de los atributos de orden financiero/ económico es recurrente que las instituciones presenten un listado de beneficios y oportunidades de becas y créditos que, muchas veces, corresponden a programas nacionales. En este sentido, no es siempre claro qué de las becas y créditos ofrecidos corresponde a la oferta institucional y qué no.

\section{4 Ámbitos de la publicidad engañosa}

De la revisión de la publicidad en el periodo de estudio no se encontraron casos evidentes de información falsa. Sin embargo, como se indicó más arriba, juzgar la publicidad como engañosa no es un asunto sencillo. De pronto, el estándar de lo engañoso está en el receptor, en la distancia con otros antecedentes, o en las discrepancias con el servicio finalmente proporcionado. Por lo mismo, es difícil sostener a priori si la publicidad tenida a la vista constituye o no publicidad engañosa.

Pese a lo anterior, se observaron numerosos casos de omisiones de información, falta de referencias respecto de las aseveraciones planteadas, o un detalle de las condiciones de las ofertas que se realizan. Son recurrentes también los mensajes aspiracionales, cuya promesa radica en la posibilidad de lograr sueños y deseos que de otro modo no pueden alcanzarse. 
Por una parte, el formato de la publicidad en prensa escrita no permite, por lo general, entregar grandes cantidades de información; por otra, mucha de la información proporcionada no es sencilla y requiere de otros antecedentes que, por lo general, no están disponibles en el mismo formato ni tampoco se indica dónde pueden ser obtenidos. Uno de los ejemplos más recurrentes está en la publicidad que se refiere a ofertas o descuentos en la matrícula y/o aranceles, pero que prácticamente nunca se informa del precio de referencia. Este sería un típico problema de integridad de la información.

Por lo general, en la publicidad de las universidades abundan antecedentes formales (listados de carreras, servicios, tipos de beneficios, etc.) y una variedad muy amplia de eslóganes y mensajes aspiracionales que invitan a matricularse y conseguir un logro académico y profesional. Mientras que los primeros son fácilmente contrastables, los segundos quedan sin embargo en el ámbito emocional, y son difícilmente verificables. Es usual encontrar que la publicidad incorpore alguna información sobre empleabilidad, selectividad, infraestructura y convenios internacionales, entre otros ámbitos, con el fin de destacar aspectos que se consideran importantes para demostrar su calidad. No obstante, por lo general se trata de información difícilmente contrastable, en muchas ocasiones referida a fuentes internas de cada institución.

Pareciera que la clave aquí está en comprender que la publicidad efectivamente proporciona información, en un formato muy particular y restringido, y que las instituciones de educación superior y la autoridad debieran complementar los antecedentes con las referencias necesarias y detalles suficientes que reduzcan los niveles de asimetría de la información entre estudiantes y universidades. Por otra parte, los mensajes que apuntan a la persuasión emocional y que invitan al logro de los deseos de los estudiantes, requiere de un tratamiento considerablemente más complejo, puesto que operan en una dimensión del establecimiento de confianzas y compromisos compartidos. 


\section{La opinión de los estudiantes}

En las entrevistas grupales realizadas, se constató que los postulantes y estudiantes de educación superior tienen una comprensión bastante clara de lo que es publicidad engañosa, noción que en términos generales se ajusta a la conceptualización consensuada en la literatura y en la ley. Ellos entienden por publicidad engañosa aquella que contiene un mensaje que no se corresponde con la realidad y que podría influir en una "mala" decisión. Esto se asocia en gran medida a la exageración de ciertos atributos y a "la letra chica" (u omisión de detalles) que implica que muchas veces "las cosas no son como te las cuentan".

Esta noción de publicidad engañosa tiene un correlato en las prácticas de los jóvenes, ya que en su experiencia de postular a la educación superior, manifiestan gran escepticismo respecto de la información que las instituciones entregan a través de su publicidad. Los estudiantes son críticos y están conscientes de las limitaciones de la publicidad como fuente de información. Al ser consultados acerca de piezas específicas, seleccionadas de la muestra 2014-2015, las reconocieron rápidamente, lo que sugiere que la publicidad de las universidades por lo general les llega y queda registrada en su memoria. Consideraron varias piezas como posiblemente "engañosas", puesto que omitían determinada información o esta no se correspondía con lo que ellos conocían de las instituciones. En este sentido, las opiniones recogidas en las entrevistas grupales sugieren que los estudiantes desconfían de la información que se les entrega, lo que coincide con otros estudios en que las audiencias son habitualmente muy críticas acerca del contenido de la publicidad (Schutz y Casey, 1981).

Los estudiantes también juzgan la publicidad por su forma y mensajes de orden emocional y simbólico. Consultados sobre piezas seleccionadas, las juzgan como "fomes" o "entretenidas"; familiares cuyo mensaje "les llega" o que les resultan ajenas y son "nada que ver".

Cabe señalar que el avisaje publicitario tradicional (en medios escritos, radios, televisión, letreros) constituye solo una fracción de la publicidad que reciben los potenciales postulantes, siendo común 
que las instituciones recurran a publicidad online en redes sociales y numerosas prácticas de marketing, como llamadas telefónicas (conociendo resultados de la PSU) y la entrega de información en la vía pública. En estos últimos casos, donde la entrega de información es verbal, los estudiantes manifiestan una postura considerablemente más crítica en relación con los mensajes e información que se les entrega. Al respecto, mencionaron casos de excesos y abusos en el uso de la información y prácticas ajenas a lo esperable en el medio académico. Si bien el escepticismo se observa en ámbitos como la calidad (sospechando de los datos, afirmaciones o indicadores que se muestran para sustentarla), la recepción crítica es más notoria respecto del financiamiento, donde las promesas de apoyo financiero (becas/créditos) contenidas en los avisos publicitarios son vistas con desconfianza. Es recurrente escuchar casos en los que los beneficios ofertados tenían condiciones que no fueron debidamente informadas en la publicidad. En este sentido, la información contenida en esta es comúnmente percibida por los estudiantes como insuficiente, por lo que se recurre a fuentes complementarias. Aunque no siempre están disponibles, los estudiantes manifestaron que las mejores fuentes de información las encontraron en portales de información pública, ferias estudiantiles y, ocasionalmente, en los prospectos institucionales que algunas universidades tienen.

Se observaron algunas diferencias en el acceso a la publicidad y comprensión de la misma entre estudiantes de distintos establecimientos. Los jóvenes que participaron en los focus group constituidos por estudiantes de establecimientos de nivel socioeconómico más alto y universidades de investigación y selectivas, tenían una comprensión mucho acabada de dónde informarse y juzgar la información de acreditación (de instituciones y carreras) que los de los focus group donde participaron estudiantes de establecimientos socioeconómicos más bajos y de universidades docentes no selectivas. Conocían mejor las fuentes de información pública disponibles y en general manifestaban contar con redes (principalmente familiares) que en la etapa de postulación eran fundamentales para informarse. 


\section{Discusión y conclusiones}

Existe un relativo consenso en la literatura respecto de la noción general de publicidad engañosa, la que a su vez se recoge en términos también generales en la legislación chilena. Los países más desarrollados han avanzado en la regulación de la publicidad a través de un conjunto amplio de iniciativas que incluyen no solo la regulación estatal, sino que también la autorregulación y diversas iniciativas de educación y organización de los consumidores. Por lo general, en aquellos países más avanzados, especialmente en Europa, la regulación de la publicidad engañosa incluye distintos tipos de faltas, desde el fraude y la mentira, hasta el engaño y los vacíos. Incluye también no solo a la publicidad tradicional, sino que también el control de los abusos y malas prácticas en marketing y publicidad no tradicional. La publicidad es una actividad relevante en contextos de competencia. Cumple funciones importantes y requiere ser desarrollada bajo principios éticos de veracidad, integridad y responsabilidad social.

La publicidad ha penetrado fuertemente en educación superior, como una práctica asociada a las dinámicas de mercado, donde las instituciones compiten por prestigio, recursos, estudiantes y profesores. La literatura acerca de publicidad en educación superior reporta un conjunto de dilemas complejos, asociados a la importación de estas prácticas a un campo que cumple funciones públicas y donde los abusos y excesos pueden terminar descentrando los principios y valores académicos tradicionales de la educación superior.

Al margen del debate en torno a las bondades o limitaciones de las dinámicas de mercado en educación superior, este sector presenta características muy particulares por las que la transparencia e información resultan clave. Se trata ciertamente de un campo de producción de servicios altamente complejos, caracterizados por una gran asimetría en la información, sea porque no es compartida por las instituciones, porque es difícil producirla o simplemente no existe. La naturaleza de los bienes generados por la educación superior tiene un impacto en las personas y la sociedad en su conjunto en el largo plazo. 
La evidencia sugiere que la publicidad está presente en parte importante de las instituciones de educación superior, cumpliendo así con sus funciones propias. No es claro que exista un estándar de gasto en esta actividad, pero ciertamente existen juicios críticos cuando alcanza dimensiones equiparables a otras industrias altamente competitivas. El gasto en publicidad parece ser ampliamente desigual, y esta investigación constató diferencias muy notorias en cuanto a la publicidad en prensa escrita entre distintos tipos de universidades en el país. Asimismo, se confirmó la existencia de un puñado de instituciones cuya presencia publicitaria es considerablemente más agresiva que el resto del sistema. El dilema pareciera presentarse cuando la publicidad alcanza niveles y contenidos que no se condicen con la función principal y las prioridades académicas de las universidades.

A juicio de los autores, existen algunos ámbitos especialmente importantes en el campo de la publicidad en educación superior y en los que hay amplio espacio para el engaño. Se trata fundamentalmente de los mensajes relativos a la calidad y a la oferta económica. Del examen de la publicidad en prensa escrita, es evidente la dificultad de encontrar información íntegra, completa y referencias suficientes para comprobar la información proporcionada, la que muchas veces se pierde entre imágenes y eslóganes que apelan a lo emocional. En este sentido, el formato de la publicidad no otorga siempre facilidades para transmitir la información asociada a servicios complejos como es la educación superior.

La legislación establece principios de integridad de la publicidad, veracidad y la posibilidad de ser comprobada, los que resultan clave en educación superior. Parte importante de la confianza pública descansa en que la publicidad, así como también el marketing en general, mantenga altos estándares de transparencia e información. Esto se traduce en la necesidad de ampliar significativamente el acceso a la información, establecer referencias y fuentes completas de respaldo para los estudiantes, particularmente respecto de los mensajes de calidad y oferta económica. Esto es igualmente válido para el componente de tipo emocional y la dimensión simbólica de la publicidad, ciertamente muy relevante y consustancial a ella, y 
respecto de la cual es indispensable construir confianza en que las promesas en el logro de los deseos son algo alcanzable y realista.

Hoy por hoy, persisten grandes vacíos respecto de la información acerca de la calidad (de profesores, recursos, empleabilidad e infraestructura, entre otros) y la oferta económica (la claridad respecto de los precios de matrícula y aranceles, porcentajes y condiciones de los beneficios, cobertura, etc.). En su ausencia, abunda en cambio una publicidad que resalta la dimensión persuasiva y emocional.

Del análisis de la regulación y opiniones de especialistas en torno a este tema, a juicio de los autores, en Chile se mantienen a lo menos tres déficits importantes en materia de regulación, que debieran ser considerados por la política pública.

El primero de ellos corresponde a un déficit de regulación pública en la educación superior. En el país hay un relativo consenso en cuanto a la necesidad de establecer una superintendencia de educación superior, con atribuciones de fiscalización y sanción de los abusos y malas prácticas en el sistema. Las iniciativas sobre su creación hasta ahora conocidas incluyen funciones de control de la publicidad engañosa. Se trata de una iniciativa de política indispensable, largamente esperada, pero que sería ingenuo pensar que basta solo con establecer multas y sanciones para erradicar la publicidad engañosa. Pareciera que son materia de regulación no solo la fiscalización y sanción a la publicidad engañosa propiamente tal, sino que especialmente las garantías de acceso a la información (por ejemplo, sobre precios, beneficios, coberturas y condiciones) y claras referencias a la calidad y experiencias de formación ofrecidas por las instituciones.

Existe también un déficit de autorregulación, sin acuerdos ni criterios compartidos por las instituciones en esta materia. Aunque la regulación estatal es indispensable, el dinamismo de las prácticas en marketing y publicidad es de tal velocidad y dinamismo en el sistema, que no es sensato que esta descanse solo en organizaciones centralizadas. Como ya se ha planteado, el campo de la educación superior tiene características particulares que llaman a establecer 
criterios propios respecto de lo que es, o no, tolerable. Esto tiene que ver con acuerdos en la comunidad de especialistas, sobre la base de las expectativas y de lo que se consideran como buenas prácticas. La publicidad engañosa puede expresarse en varios ámbitos, así también como en prácticas de marketing y diversos modos de comunicación y contacto. Lo más visible es la publicidad en medios tradicionales. Sin embargo, su creciente presencia en medios no tradicionales (contactos personales, llamadas telefónicas, contactos a través de redes sociales) y prácticas agresivas de marketing (promotoras con firma de contratos en la calle, regalos por matricularse, propaganda y giras para los colegios, etc.), son las que causan más malestar entre los estudiantes. Muchas instituciones critican a otras por sus excesos en esta materia, pero no han estado disponibles para fijar criterios apropiados al medio de la educación superior. Urge, pues, establecer acuerdos razonables entre las universidades y criterios que establezcan límites respecto de la cantidad, características y formatos de la publicidad. Esta tarea podría ser realizada por el CRUCH u otra organización que agrupe a las instituciones. La experiencia de autorregulación en otros campos, realizada con el apoyo de organizaciones independientes de control ético de la publicidad, podría constituir un buen ejemplo a seguir en educación superior. Igualmente, las universidades podrían contribuir también en fijar estándares sobre el contenido de la información mínima que debiera estar siempre disponible para entregar a los postulantes y estudiantes.

Finalmente, es evidente la asimetría entre estudiantes e instituciones, la que exige formar adecuadamente a los primeros en sus derechos y fortalecer los mecanismos para que puedan ejercerlos debidamente. Es clave la existencia de canales expeditos de comunicación y de reclamo, dentro de las instituciones y fuera de ellas, con compromisos claros de respuesta oportuna y transparente. También parece importante revisar los procedimientos y apoyo a los estudiantes para ejercer su derecho a reclamo en la justicia y sancionar adecuadamente los casos de abusos y publicidad engañosa. La casuística sobre la materia sugiere que hay todavía mucho por hacer, fortaleciendo la posición de ellos y sujetando a las instituciones responsablemente respecto de los compromisos asumidos en sus mensajes publicitarios. 
Como se ha planteado en este trabajo, el problema de la publicidad engañosa daña las bases de la confianza y fe pública en el sistema. Se trata de un problema complejo, que responde a dinámicas profundas de funcionamiento del sistema, pero que puede ser regulado y controlado mediante un conjunto de iniciativas de política que involucran al menos al Estado, a las instituciones y a los estudiantes.

\section{Referencias}

Anctil, E. J. (2008). Selling higher education: Marketing and advertising America's colleges and universities. Special Issue, ASHE Haigher Education Report, 34(2). San Francisco, CA: Jossey-Bass Inc Pub.

Askehave, I. (2007). The impact of marketization on higher education genres - the international student prospectus as a case in point. Discourse Studies, 9(6), 723-742. http://dx.doi.org/10.1177/1461445607082576

Bernasconi, A. (1994). La privatización de la educación superior en Chile y la regulación a través del mercado. Estudios Sociales, 82(4), 9-24.

Bigne, E., Andreu, L. y Rodríguez, M. (2000). Una aproximación a la tipología de la publicidad ecológica. Esic Market, 105, 97-114.

Bok, D. (2009). Universities in the marketplace: The commercialization of higher education. Princeton, NJ: Princeton University Press.

Bradley, J. (2013). Integrity in higher education marketing? A typology of misleading data-based claims in the university prospectus. International Journal for Educational Integrity, 9(2), 74-88.

Briggs, S. (2006). An exploratory study of the factors influencing undergraduate student choice: The case of higher education in Scotland. Studies in Higher Education, 31(6), 705-722. http://dx.doi. org/10.1080/03075070601004333

Briggs, S. \& Wilson, A. (2007). Which university? A study of the influence of cost and information factors on Scottish undergraduate choice. Journal of Higher Education Policy and Management, 29(1), 57-72. http://dx. doi. org/10.1080/13600800601175789

Brown, R. (2007). The information fallacy. Recuperado de http//:www.hepi. ac.uk/2007/03/29/the-information-fallay/

Brunner, J. J. (1993). Chile's higher education: Between market and state. Higher Education, 25(1), 35-43. http://dx.doi.org/10.1007/bf01384040 
Brunner, J. J. (1997). From state to market coordination: The Chilean case. Higher Education Policy, 10(3-4), 225-237. http://dx.doi.org/10.1016/ s0952-8733(97)00015-9

Brunner, J. J. (2004). Políticas y mercados de educación superior: necesidades de información. En J. J. Brunner \& P. Meller (Comps.), Oferta y demanda de profesionales y técnicos en Chile (pp. 19-85). Santiago de Chile: Ril Editores.

Brunner, J. J. (2008a). Educación superior en Chile: instituciones, mercados y políticas gubernamentales, 1967-2007. (Tesis doctoral inédita). Leiden: Leiden University.

Brunner, J. J. (2008b). El sistema de educación superior en Chile: un enfoque de economía política comparada. Avaliação: Revista da Avaliação da Educação Superior, 13(2), 451-486. http://dx.doi.org/10.1590/S141440772008000200010

Brunner, J. J. (2009). Tipologías y características de las universidades chilenas. Documento de trabajo, Centro de Políticas Comparadas en Educación, Universidad Diego Portales. Recuperado de http//: 200.6.99.248/ bru487cl/files/Tipol\%26Caract_080209.pdf

Brunner, J. J., Elacqua, G., Tillett, A., Bonnefoy, J., González, S., Pacheco, P. y Salazar, F. (2005). Guiar el mercado. Informe sobre la educación superior en Chile. Santiago de Chile: Universidad Adolfo Ibáñez.

Brunner, J. J. y Uribe, D. (2007). Mercados universitarios: el nuevo escenario de la educación superior. Santiago de Chile: Ediciones Universidad Diego Portales.

Cámara de Diputados. (2012). Informe de la comisión investigadora sobre el funcionamiento de la educación superior. Congreso de Chile. Recuperado de htpps://www.camara.cl/trabajamos/comision_ informesComision.aspx?prmID=706

Capriotti, P. (2009). Branding corporativo. Santiago de Chile: Colección Libros de la Empresa.

Comisión Nacional de Acreditación, CNA (2013). Circular No 19 imparte instrucciones de carácter general a las instituciones de educación superior sobre la forma y oportunidad en que deberán informar al público respecto de los procesos de acreditación institucional, pregrado, postgrado y especialidades en el área de la salud. Santiago de Chile: Autor. Recuperado de https://www.cnachile.cl/Paginas/ observacionespublicidad.aspx

Clark, B. (1983). The higher education system. Academic organization in crossnational perspective. Berkeley, CA: University of California Press. http:// dx.doi.org/10.2307/2392705 
Consejo Superior de Educación, CSE. (2001). Información en la educación superior, necesidades y propuestas. Informe final. Santiago de Chile: Consejo Superior de Educación.

Consejo Superior de Educación, CSE. (2011). Equidad en el acceso a la educación superior. Santiago de Chile: Consejo Superior de Educación.

Constantinides, E. \& Stagno, M. C. Z. (2013). Higher education marketing: A study on the impact of social media on study selection and university choise. En P. Tripathi \& S. Mukerji (Eds.), Marketing strategies for higher education institutions: Technological considerations and practices (pp. 128-147). Hershey, PA: Business Science Reference (IGI Global)

Constantinides, E. \& Zinck Stagno, M. C. (2011). Potential of the social media as instruments of higher education marketing: A segmentation study. Journal of Marketing for Higher Education, 21(1), 7-24. http://dx.doi.or g/10.1080/08841241.2011.573593

Creswell, J. W. \& Clark, V. L. P. (2007). Designing and conducting mixed methods research. California: SAGE Publications.

Curubeto, C. (2007). La marca universitaria, atributos, beneficios o valores: ¿Qué utilizan las universidades de Buenos Aires para construir su identidad de marca y su propuesta de valor? Buenos Aires: Editorial Dunken.

Delgado, J. B. (1997). Lenguaje publicitario. Madrid: Síntesis.

Dill, D. (1997). Higher education markets and public policy. Higher Education Policy, 10(3-4), 167-185.

Durán-Pich, A. (1982). Psicología de la publicidad y de la venta. Barcelona: CEAC.

Durandin, G. (1990). La mentira en la propaganda política y en la publicidad. Barcelona: Paidós.

Edmiston-Strasser, D. M. (2009). An examination of integrated marketing communication in US public institutions of higher education. Journal of Marketing for Higher Education, 19(2), 142-165.

Engel, E. (1998). Protección a los consumidores en Chile: ¿Por qué tan poco y tan tarde? Santiago de Chile: Centro de Economía Aplicada, Universidad de Chile.

Espinoza, Ó. (2005). Privatización y comercialización de la educación superior en Chile: una visión crítica. Revista de la Educación Superior, 34(135), 41-60.

Espinoza, Ó. (2008). Creating (in) equalities in access to higher education in the context of structural adjustment and post-adjustment policies: The case of Chile. Higher Education, 55(3), 269-284. http://dx.doi. org/10.1007/s10734-007-9054-8 
Ewen, S. (2008). Captains of consciousness: Advertising and the social roots of the consumer culture. New York, NY: Basic Books.

Fairclough, N. (1993). Critical discourse analysis and the marketization of public discourse. Discourse and Society, 4(2), 133-168. http://dx.doi. org/10.1177/0957926593004002002

Fairweather, J. (2009). U.S. higher education: Contemporary challenges, policy options. In D. Palfreyman \& T. Tapper (Eds.), Structuring mass higher education: The role of elite institutions (pp. 13-34). New York \& Oxon: Routledge.

Fernández, F. (2005). La nueva institucionalidad de la protección de los derechos de los consumidores en nuestro país a partir de la Ley 19.955. En Centro de Derechos Humanos, Universidad de Chile, Anuario de Derechos Humanos (pp. 111-115). Santiago de Chile: Autor.

Gardner, D. M. (1975). Deception in advertising: A conceptual approach. The Journal of Marketing, 39(1), 40-46.

Gibbs, P. (2007). Does advertising pervert higher education? Is there a case for resistance? Journal of Marketing for Higher Education, 17(1), 3-11. http://dx.doi.org/10.1300/j050v17n01_02

Guzmán, J. A. (2014). La gran estafa: cómo opera el lucro en la educación superior. Santiago de Chile: Universidad Diego Portales.

Hastak, M. \& Mazis, M.B. (2011). Deception by implication: A typology of truthful but misleading advertising and labeling claims. Journal of Public Policy \& Marketing, 30(2), 157-167. http://dx.doi.org/10.1509/ jppm.30.2.157

Hemsley-Brown, J. \& Oplatka, I. (2006). Universities in a competitive global marketplace: A systematic review of the literature on higher education marketing. International Journal of Public Sector Management, 19(4), 316-338. http://dx.doi.org/10.1108/09513550610669176

Jongbloed, B. (2003). Marketization in higher education, Clark's triangle and the essential ingredients of markets. Higher Education Quarterly, 57(2), 110-135. http://dx.doi.org/10.1111/1468-2273.00238

Kirp, D. (2004). Shakespeare, Einstein, and the bottom line: The marketing of higher education. Cambridge, MA: Harvard University Press.

Kittle, B. (2000). Institutional advertising in higher education. Journal of Marketing for Higher Education, 9(4), 37-52. http://dx.doi.org/10.1300/ j050v09n04_03

Klassen, M. L. (2001). Lots of fun, not much work, and no hassles: Marketing images of higher education. Journal of Marketing for Higher Education, 10(2), 11-26. http://dx.doi.org/10.1300/j050v10n02_02 
Krueger, R. A. \& Casey, M. A. (2009). Focus groups: A practical guide for applied research. Thousand Oaks, CA: Sage Publication.

Latorre, C. L., González, L. E. y Espinoza, Ó. (2008). Política pública en educación superior desde el punto de vista de la equidad: el caso de Chile. Santiago de Chile: Fundación Equitas.

Ley $\mathrm{N}^{\circ} 19.496$ establece normas sobre protección de los derechos de los consumidores del Ministerio de Economía. Diario Oficial de la República de Chile, Santiago, Chile, 7 de marzo de 1997.

Ley No 20.129 establece un Sistema Nacional de Aseguramiento de la Calidad de la Educación Superior del Ministerio de Educación. Diario Oficial de la República de Chile, Santiago, Chile, 17 de noviembre de 2006.

Ley No 20.370 establece la Ley general de Educación. Diario Oficial de la República de Chile, Santiago, Chile, 12 de septiembre de 2009.

Ley $\mathrm{N}^{0} 20.800$ crea el administrador provisional y el administrador de cierre de instituciones de educación superior y establece regulaciones en materia de administración provisional de sostenedores educacionales. Diario Oficial de la República de Chile, Santiago, Chile, 26 de diciembre de 2014.

Macfarlane, B., Zhang, J., \& Pun, A. (2014). Academic integrity: A review of the literature. Studies in Higher Education, 39(2), 339-358. http:// dx.doi.org/10.1080/03075079.2012.709495

Marginson, S. (2006). Dynamics of national and global competition in higher education. Higher Education, 52(1), 1-39. http://dx.doi.org/10.1007/ s10734-004-7649-x

Maringe, F. \& Gibbs, P. (2008). Marketing higher education: Theory and practice. New York and Maidenhead, UK: McGraw-Hill Education.

Mayer, R. N. (1989). The consumer movement: Guardians of the marketplace. Boston, MA: Twayne Pub.

Meller, P. (2004). La universidad y el mercado. Santiago de Chile: Departamento de Ingeniería Industrial, Universidad de Chile.

Meller, P. (2011). Universitarios, el problema no es el lucro es el mercado. Santiago de Chile: Uqbar.

Monckeberg, M. O. (2011). El negocio de las universidades en Chile. Santiago de Chile: Debolsillo.

Noguero, A. M. (2007). Diferencias conceptuales entre publicidad y propaganda: una aproximación etimológica. Questiones Publicitarias: Revista Internacional de Comunicación y Publicidad, 12(1), 43-61. 
Oplatka, I. \& Hemsley-Brown, J. (2004). The research on school marketing: Current issues and future directions. Journal of Educational Administration, 42(3), 375-400. http://dx.doi.org/10.1108/09578230410534685

Organización para la Cooperación y el Desarrollo Económicos, OCDE. (2009). Revisión de politicas nacional de educación: la educación superior en Chile. Santiago de Chile: OCDE \& Banco Mundial.

Peña, C. (2011). Publicidad universitaria, ¿buena o mala? En Consejo Superior de Educación, CSE (Ed.), Equidad en el acceso a la educación superior (pp. 93-99). Santiago de Chile: Autor.

Presidencia de la República (2011). Mensaje Presidencial No 277-359 acerca del Proyecto de ley de creación de la Superintendencia de Educación Superior. Valparaíso: Boletín 9.369-03, Cámara de Diputados.

Rao, H. (1998). Caveat emptor: The construction of nonprofit consumer watchdog organizations 1. American Journal of Sociology, 104(4), 912961.

Rhoades, G. \& Slaughter, S. (2004). Academic capitalism in the new economy: Challenges and choices. Baltimore, MD: Johns Hopkins University Press.

Russo, J.E., Metcaf, B.L., \& Stephens, D. (1981). Identifying misleading advertising. Journal of Consumer Research, 8(2), 119-131.

Salazar, J. y Leihy, P. (2013). El manual invisible: tres décadas de políticas de educación superior en Chile (1980-2010). Education Policy Analysis Archives, 21(34), 1-34. http://dx.doi.org/10.14507/epaa.v2ln34.2013

Schoenmakers, G. (2000). La publicidad engañosa y su regulación en Chile. (Tesis inédita), Pontificia Universidad Católica, Santiago, Chile.

Schutz, H. G. \& Casey, M. (1981). Consumer perceptions of advertising as misleading. Journal of Consumer Affairs, 15(2), 340-357.

Semprini, A. (1995). El marketing de la marca: una aproximación semiótica. Barcelona: Paidós Ibérica.

Senado de la República de Chile (2013). Informe de la Comisión de educación, cultura, ciencia y tecnología, recaído en el proyecto de ley, en primer trámite constitucional, que crea la Superintendencia de Educación Superior. Valparaíso: Boletín No 8.041-04. Cámara de Diputados.

Sevier, R. A. (2001). Brand as relevance. Journal of Marketing for Higher Education, 10(3), 77-97. http://dx.doi:10.1300/J050v10n03_05

Soto, E. M. I. (2010). Aproximación a la publicidad engañosa, desde la perspectiva de la competencia desleal y la protección al consumidor. Ars Boni et Aequi, 6(1), 125-148. 
Sotomayor, A. y Muga, A. (2004). La diferenciación por calidad: ¿Cuáles son los límites? Revista Calidad en la Educación, 21(1), 47-60.

Squella, A. (2001). La información en el marco de la calidad de la educación superior. Información en la educación superior: necesidades y propuestas. En Consejo Superior de Educación, Información en la educación superior, necesidades y propuestas (pp.22-32). Santiago de Chile: Autor.

Trow, M. (1996). Trust, markets and accountability in higher education: A comparative perspective. Higher Education Policy, 9(4), 309-324.

Worner, C. \& Santander, P. (2012). Marketing en la educación universitaria chilena. (Documento no publicado) P. Universidad Católica de Valparaíso, Valparaíso, Chile.

Zapata, G. (2011). Necesidades y provisión de información en el contexto público/privado de la educación superior chilena. En J. J. Brunner \& C. Peña (Eds.), El conflicto de las universidades: entre lo público y lo privado (pp. 331-363). Santiago de Chile: Ediciones Universidad Diego Portales.

Zapata, G. y Fleet, N. (2012). Mercado, rendición de cuentas e información pública en educación superior. Estudios Pedagógicos, 38(1), 259-276.

Zapata, G., Tejeda, I., y Rojas, Á. (2011). La educación superior en Chile. En Centro Interuniversitario de Desarrollo, Cinda (Ed.), La educación superior en Iberoamérica 2011 (Anexo, pp. 1-71). Santiago de Chile: Autor.

Zemsky, R., Wegner, G. R., \& Massy, W. F. (2005). Remaking the American university: Market-smart and mission-centered. New Brunswick, NJ and London: Rutgers University Press.

Recibido: 05/01/2016

Aceptado: 11/03/2016 